\title{
Eating down or simply eating less? The diet and health implications of these practices during pregnancy and postpartum in rural Bangladesh
}

\author{
Kassandra L Harding ${ }^{1,2}$, Susana L Matias ${ }^{1}$, Malay K Mridha ${ }^{1,3}$, Stephen A Vosti ${ }^{1}$, \\ Sohrab Hussain ${ }^{3,4}$, Kathryn G Dewey ${ }^{1}$ and Christine P Stewart ${ }^{1, *}$ \\ ${ }^{1}$ Program in International and Community Nutrition, Department of Nutrition, University of California, Davis, \\ 1 Shields Avenue, Davis, CA 95616, USA: ${ }^{2}$ Friedman School of Nutrition Science and Policy, Tufts University, \\ Boston, MA, USA: ${ }^{3}$ International Center for Diarrhoeal Disease Research, Bangladesh, Dhaka, Bangladesh: \\ ${ }^{4}$ Save the Children, Dhaka, Bangladesh
}

Submitted 1 July 2016: Final revision received 6 January 2017: Accepted 27 March 2017: First published online 20 June 2017

\begin{abstract}
Objective: To: (i) determine the prevalence of self-reported eating less and eating down during early and late pregnancy and postpartum, and explore risk factors associated with eating less; (ii) examine the association between eating less and diet quality; and (iii) determine the association between eating less and weight gain during pregnancy.

Design: Data were collected longitudinally from a cohort of women participating in a community health programme. Diet was assessed at three time points ( $\leq 20$ weeks' gestation, 36 weeks' gestation, 6 months' postpartum), body weight was measured during study enrolment ( $\leq 20$ weeks' gestation) and at 36 weeks' gestation, and information about the woman and her household was collected at enrolment.

Setting: The Rang-Din Nutrition Study in the Rangpur and Dinajpur districts of Bangladesh.

Subjects: Women ( $n$ 4011).

Results: The prevalence of self-reported eating less differed by time point $(75.9 \%$ in early pregnancy, $38.8 \%$ in late pregnancy, $7.4 \%$ postpartum; $P<0.001)$. The most common reason for eating less across all time periods was food aversion or loss of appetite. Women who reported eating less in late pregnancy had consumed animal-source foods less frequently in the preceding week than women who reported eating more (mean (SD): 11.7 (7.4) v. 14.8 (9.2) times/week; $P<0.001)$ and had lower weekly weight gain than women who reported eating more (mean (se): 0.27 (0.004) v. 0.33 (0.004) kg/week; $P<0.001)$.

Conclusions: Eating less has negative implications with respect to diet quality and pregnancy weight gain in this context.
\end{abstract}

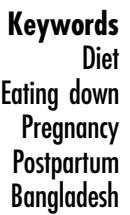

Pregnancy is a critical period for the health of both the woman and her fetus ${ }^{(1)}$, yet it is also a time during which nutrient requirements are increased and risk of nutritional inadequacy is high ${ }^{(2,3)}$. This is particularly true in low- and middle-income countries where diet quality is typically poor and intake is often inadequate even prior to pregnancy. Bangladesh has a high burden of undernutrition among both children and women. In 2014, the prevalence of underweight (BMI $<18.5 \mathrm{~kg} / \mathrm{m}^{2}$ ) and short stature (height $<145 \mathrm{~cm}$ ) among ever-married women aged 15-49 years was 19 and $13 \%$, respectively ${ }^{(4)}$. In a crosssectional study of children and women in Mymensingh and Rangpur districts of Bangladesh using $12 \mathrm{~h}$ weighed food records and $12 \mathrm{~h}$ diet recalls, the mean $(\mathrm{sD})$ prevalence of adequate intake of eleven micronutrients among women was $26(10) \%^{(5)}$. The prevalence of adequacy was even lower for $\mathrm{Fe}(16 \%), \mathrm{Zn}(22 \%)$, vitamin $\mathrm{B}_{12}(1 \%)$, folate (0\%), vitamin A (3\%) and Ca (0\%). Among this same study population of women, $84 \%$ of energy came from rice, suggesting that the dietary inadequacies are due to poor nutrient density in the diet and low dietary diversity ${ }^{(6)}$.

While diets of non-pregnant women in Bangladesh are poor, the problem can be exacerbated during pregnancy and lactation due to factors such as pregnancyrelated food aversions, cultural beliefs about diet during pregnancy and postpartum, and household food insecurity. 
Of even greater concern is evidence suggesting that many pregnant women eat less compared with their prepregnancy intake for various reasons. For example, in one national survey, $32 \cdot 8 \%$ of women reported eating less food during their previous pregnancy compared with their usual pre-pregnancy intake ${ }^{(7)}$. In that study, knowledge that 'increased consumption during pregnancy is optimal' was reported as the most significant factor associated with increased intake, although maternal education, number of antenatal visits, number of meals consumed and money spent on food were also associated with eating more. A small mixed-methods study examining the social and environmental factors related to maternal malnutrition in rural Barisal district, in southern Bangladesh, found that $12.2 \%$ of women reported eating less food during their previous pregnancy compared with their usual prepregnancy intake ${ }^{(8)}$. The primary barriers to increasing food intake were discriminatory food allocation (90\%), lack of decision-making power (85\%), lack of family support (67\%), economic and access constraints (50\%), illness (46\%) and concerns about the size of the baby (20\%).

The behaviour of purposefully eating less due to sociocultural beliefs, what we refer to herein as 'eating down', has been cited in the literature over the past three decades with respect to diets during pregnancy in Asian countries, including India ${ }^{(9-13)}$, Pakistan ${ }^{(14,15)}$, Indonesia ${ }^{(16)}, \mathrm{Nepal}^{(17)}$ and Bangladesh ${ }^{(7,8)}$. The prevalence of eating down is not well documented, and more recent investigations suggest that it is declining ${ }^{(8,17)}$, although eating less food during pregnancy is still common. A survey in the rural Sarlahi district in Nepal found that $60 \%$ of women reported eating less food or rice during pregnancy, but that a lower percentage of women decreased intake of micronutrient-dense foods $(<20 \%)^{(17)}$. The consequences of eating less in terms of diet quality and the ultimate impact on pregnancy weight gain and other health outcomes are not well documented.

The current study had three objectives: (i) to provide new data on the prevalence of eating less and eating down, identify the reasons reported for this behaviour during early pregnancy, late pregnancy and postpartum, and explore risk factors associated with eating less in late pregnancy; (ii) to examine the association between eating less and diet quality; and (iii) to determine the association between eating less and weight gain during pregnancy.

\section{Methods}

The present evaluation was conducted as a part of the Rang-Din Nutrition Study, a longitudinal clusterrandomized trial to evaluate the effectiveness of lipidbased nutrient supplements provided to pregnant and lactating women and their children with regard to nutritional and health outcomes. Details of the study methods have already been published ${ }^{(18)}$ In brief, LAMB, a local non-governmental organization, implemented the interventions of the effectiveness trial through its Community Health and Development Program in eleven unions in the Rangpur and Dinajpur districts in north-west Bangladesh from September 2011 through May 2015. Women were eligible for enrolment in the evaluation if they were $\leq 20$ weeks' gestation and had no plans to move out of the study area for approximately the next 3 years. Community health workers (CHW) identified new pregnancies through active surveillance from September 2011 through August 2012 and confirmed pregnancies with a urine strip test. Women participating in the programme were provided with lipid-based nutrient supplements (LNS arm) from pregnancy through 6 months postpartum or iron and folic acid tablets (IFA arm) from pregnancy through 3 months postpartum, depending on their cluster assignment. Standard messages primarily about the supplements were provided to all women participating in the study (see online supplementary material, Supplemental Information).

Trained enumerators visited the women's homes at enrolment, 35 weeks' gestation and 6 months' postpartum, and women visited safe delivery units (SDU) at enrolment and 36 weeks' gestation for interviews and assessments. Information regarding socio-economic and demographic characteristics, food security, and knowledge, attitudes and practices regarding maternal nutrition were collected at the women's homes at enrolment. An asset index was developed using principal components analysis and women were classified into household food security categories according to the Household Food Insecurity Access Scale ${ }^{(19)}$. Women were asked to recall their last menstrual period, which was used to determine gestational age at enrolment and to schedule the 35 and 36 weeks' gestation visits at the home and SDU, respectively. Medical history and anthropometric measurements were taken at the first SDU visit and the woman's weight was measured again at the SDU at 36 weeks' gestation.

Women's diets were assessed at the women's homes at enrolment (early pregnancy), 35 weeks' gestation (late pregnancy) and 6 months' postpartum (postpartum).

Diets were assessed using an eighteen-item $7 \mathrm{~d}$ FFQ. Foods were chosen because they were suspected to be consumed less during pregnancy or they represented important nutrient sources in a typical diet in this region of Bangladesh. At each of the three interviews women were asked to recall the number of times and days they consumed specific food items in the past $7 \mathrm{~d}$. Women were also asked to describe their overall diet in terms of amount of food ('Compared to your overall diet before you were pregnant, are you consuming more, less or the same amount of food?') and number of meals they currently consumed ('Compared to the number of meals you ate each day before you were pregnant, are you consuming more, less or the same number of meals?') 
compared with their pre-pregnancy diet. For these two questions women could respond that they were consuming (i) more, (ii) the same or (iii) less compared with their pre-pregnancy diet. If a woman reported 'more' or 'less', she was asked to provide the reason(s) for the change in diet pattern. These questions were open ended and women could provide more than one reason. At each time point, women were also asked if they were currently avoiding any foods and, if so, which foods. Finally, at 35 weeks' gestation, women were also asked to compare their current consumption of each FFQ food item with their pre-pregnancy intake of that food ${ }^{(17)}$. Data on specific quantities of foods consumed were not collected.

Several variables were derived from this FFQ. Women who reported eating less food were further classified at the time of the analysis into a subgroup who were eating down if they reported eating less for any of the following reasons to an open-ended question: (i) concerned about the health of her baby; (ii) concerned about her own health; (iii) concerned about too much weight gain; (iv) concerned about difficult labour; (v) concerned about the size of the baby being too large; or (vi) religious beliefs. Food group variables were also created based on FFQ data. Animal-source foods (ASF) included the sum of the number of times women reportedly consumed any meat, poultry, eggs, fish, dried fish, milk and other dairy products. Because milk and other dairy products are consumed in very small quantities (e.g. milk in tea), each time they were reported they were given half the weight compared with the other foods. Red and green leafy vegetables (RGLV) included the sum of the number of times green leafy vegetables and red leafy vegetables were consumed. Vitamin C-rich foods included the sum of the number of times Indian jujubes, guava, mango and pineapple were consumed.

At enrolment and 36 weeks' gestation, maternal weight was measured twice by trained anthropometrists at the SDU and recorded to the nearest $0.1 \mathrm{~kg}$ (adult scale, Seca 874). Measurements were repeated a third time if the first two measurements were not within a pre-specified error tolerance. The mean of the two closest weight measurements was used for analysis. Weekly weight gain was calculated as the weight at 36 weeks' gestation minus the weight at enrolment, divided by number of weeks between the two measurements.

Two women not involved in other study activities and trained in qualitative methods conducted semi-structured in-depth interviews among a purposively selected subsample of women in the LNS arm, from four of the eleven unions. The primary purpose was to understand variability in adherence to LNS recommendations. Additionally, beliefs and practices regarding diet during pregnancy were also discussed. In the present paper, we concentrate on the section of the interviews that focused on the quantity of food for pregnant women. In-depth interviews were conducted among trial participants ( $n$ 16), family members of participants (including mothers-in-law, sisters-in-law and husbands; $n$ 10) and CHW ( $n$ 8). Details regarding these interviews have already been published ${ }^{(20)}$.

Quantitative data were double-entered into an Oracle database and converted to SAS for Windows version 9.3 for analysis. Each outcome variable was checked separately for outliers, errors and variable transformation, as needed. After transcription, translation and review, the Microsoft Word files of English transcripts of the in-depth interviews were imported into NVivo version 10 for analysis.

\section{Statistical analyses}

We used mixed-model ANOVA and logistic regression (PROC GLIMMIX) to evaluate continuous and dichotomous outcomes, respectively, accounting for the subject and cluster effect where appropriate. Factors considered in multivariate models were based on an a priori theoretical framework linking each factor with the outcome of the analysis. We evaluated the need to account for intervention group in our models and found that it was not a significant covariate or effect modifier in this analysis, so it was not included in our final models. Pairwise differences were tested adjusting for multiple comparisons using the Tukey-Kramer method.

Separate models were used to evaluate the dichotomous dependent variables of eating less food, eating down, eating fewer number of meals and avoiding foods across the three time points of interest: early pregnancy, late pregnancy and postpartum. Due to the high collinearity between the subject effect and cluster effect, the cluster effect was removed from models that would not converge otherwise. The same approach was used to examine factors associated with eating less food in late pregnancy and associations between consuming less of specific foods and consuming less food overall in late pregnancy.

To evaluate the consequences of eating less on diet quality, mixed-model ANOVA was used. Diet quality was defined based on the number of times ASF, lentils and RGLV were consumed in the previous week as a continuous variable. These variables were not normally distributed and suitable transformations were explored. For ASF consumption, we found that a square-root transformation provided the best fit, while for lentils and RGLV a negative binomial provided the best fit. We evaluated the relationship for all time points aggregated (PROC GLIMMIX) and stratified by time point (PROC GENMOD). Season was controlled for in the models by including a categorical season variable as a covariate in each model, standard errors were adjusted for the effect of cluster and subject, and the Tukey-Kramer adjustment for multiple comparisons was used.

Mixed-model ANOVA was used to evaluate the association between eating less and weight gain during pregnancy. Weight gain was log-transformed for analysis and the model adjusted for maternal age, BMI and 
gestational age at enrolment, parity, and season of interview at 36 weeks' gestation.

Constant comparison analysis ${ }^{(21)}$ was used to analyse perceptions about the amount of food pregnant women should consume, as documented in the in-depth interviews. One investigator (K.L.H.) coded all of the respondents' discussions regarding amount of food into three umbrella codes: more, less, same. She then reviewed the responses by each group of respondents (CHW, women, relatives) and proceeded to develop overarching themes.

This study was approved by the UC Davis Institutional Review Board, the Ethical Review Committee of the International Center for Diarrhoeal Disease Research, Bangladesh and the LAMB Research Ethics Committee. Women indicated their written consent to participate in the study after a consent form was read to them. If a participant was less than 18 years old, her guardian signed the consent form on her behalf and participants who could not write provided consent with a thumbprint.

\section{Results}

Between September 2011 and August 2012, 5490 pregnant women were identified through the programme (Fig. 1). In total, 4011 women were enrolled, 3280 were visited at their homes at approximately 35 weeks' gestation, 2937 completed the 36 weeks' visit and 3689 completed the 6 months' postpartum home visit. Baseline characteristics of the women are summarized in Table 1.

Eating down was reported rarely $(<4 \%)$ during any period, although the most common reason reported was concern about own health. In contrast, there were high rates of eating less during pregnancy, estimated at $75.9 \%$ in early pregnancy, $38.8 \%$ in late pregnancy and $7.4 \%$ in postpartum $(P<0 \cdot 001$; Table 2$)$. A similar pattern was seen with the reported change in number of meals women consumed during these three periods. The most common reasons reported for eating less were food aversions or loss of appetite (75.4\%), followed by illness (49.2\%) and nausea and vomiting (41.0\%; Table 3). Of the 4589 women who reported eating less food, 3222 gave more than one reason for doing so. Approximately $43.5 \%$ of these women reported both nausea and vomiting and food aversions or loss of appetite, $41.0 \%$ reported both illness and food aversions or loss of appetite, and $26 \cdot 1 \%$ reported both nausea and vomiting and illness. We also found that $16 \cdot 6 \%$ of these women reported all three reasons: food aversions or loss of appetite, illness, and nausea and vomiting. Similar reasons were reported for eating fewer meals (see online supplementary material, Supplemental Table 1). Reported avoidance of specific foods was most prevalent in the postpartum (42.8\%) and least prevalent in late pregnancy $(21.0 \%)$ and differed significantly across the three time points $(P<0 \cdot 001)$.
Several demographic and socio-economic factors were associated with eating less (Table 4). Primigravid women $(\mathrm{OR}=0.59 ; 95 \% \mathrm{CI} 0.51,0.69)$, women $<20$ years old $(\mathrm{OR}=0.71 ; 95 \% \mathrm{CI} 0.61,0.82)$, women with a primaryschool education or less compared with women with greater than a primary-school education $(\mathrm{OR}=1.51$; $95 \%$ CI 1.30, 1.75) and those living in a joint family as opposed to a single family (OR=0.71; $95 \%$ CI 0.60, 0.83) had lower odds of reporting eating less in late pregnancy. Food insecurity was associated with eating less and women who held the belief that women should eat less during pregnancy were more likely to eat less themselves.

\section{Qualitative assessment of pregnancy diet patterns}

In-depth interviews with women, family members and CHW revealed the following common beliefs: (i) women should eat more during pregnancy; (ii) pregnant women need to eat more frequent meals of smaller portions; (iii) pregnant women are eating for two; and (iv) there are challenges to eating more during pregnancy. While most respondents stated that pregnant women should eat more, some raised concerns about pregnant women consuming more food. One husband interviewed explained his concern that when a woman consumes too much, 'the child in the womb may have a problem or the child's mother may have a problem'. Further, some respondents alluded to a fear of a caesarean delivery if the baby became too big. While these quotes illustrate that there are still beliefs that are consistent with eating down, the majority of respondents explained that women should eat more while pregnant. Many respondents reported that pregnant women should eat more frequent meals. This was also coupled with an explanation that pregnant women cannot eat as much food at one time, so they should eat smaller portions more often. One sister-in-law explained: 'It may be four or five times a day. Before becoming pregnant, three times a day should be eaten. She should eat a little amount at a time and repeatedly when she is pregnant.' However, respondents disagreed on the specific number of times a pregnant woman should eat, ranging from an increase of two handfuls of rice per day to eating eight times in a day. Eating for two was commonly cited in interviews with $\mathrm{CHW}$ and women, but was not a strong theme among family members. One CHW speaking about pregnant women explained: 'She should remember that she is like two people ... she should take the food for two people.' Many CHW, women and family members acknowledged the challenges pregnant women face in consuming more food due to poor appetite, illness, nausea and vomiting. For example, a woman explained the challenge to increasing food consumption during pregnancy: 'During pregnancy one cannot take as much as she could take before pregnancy ... A little more than that [amount before they were pregnant] should be taken but they cannot. In fact, one can hardly take that much ... Oh, mother! 


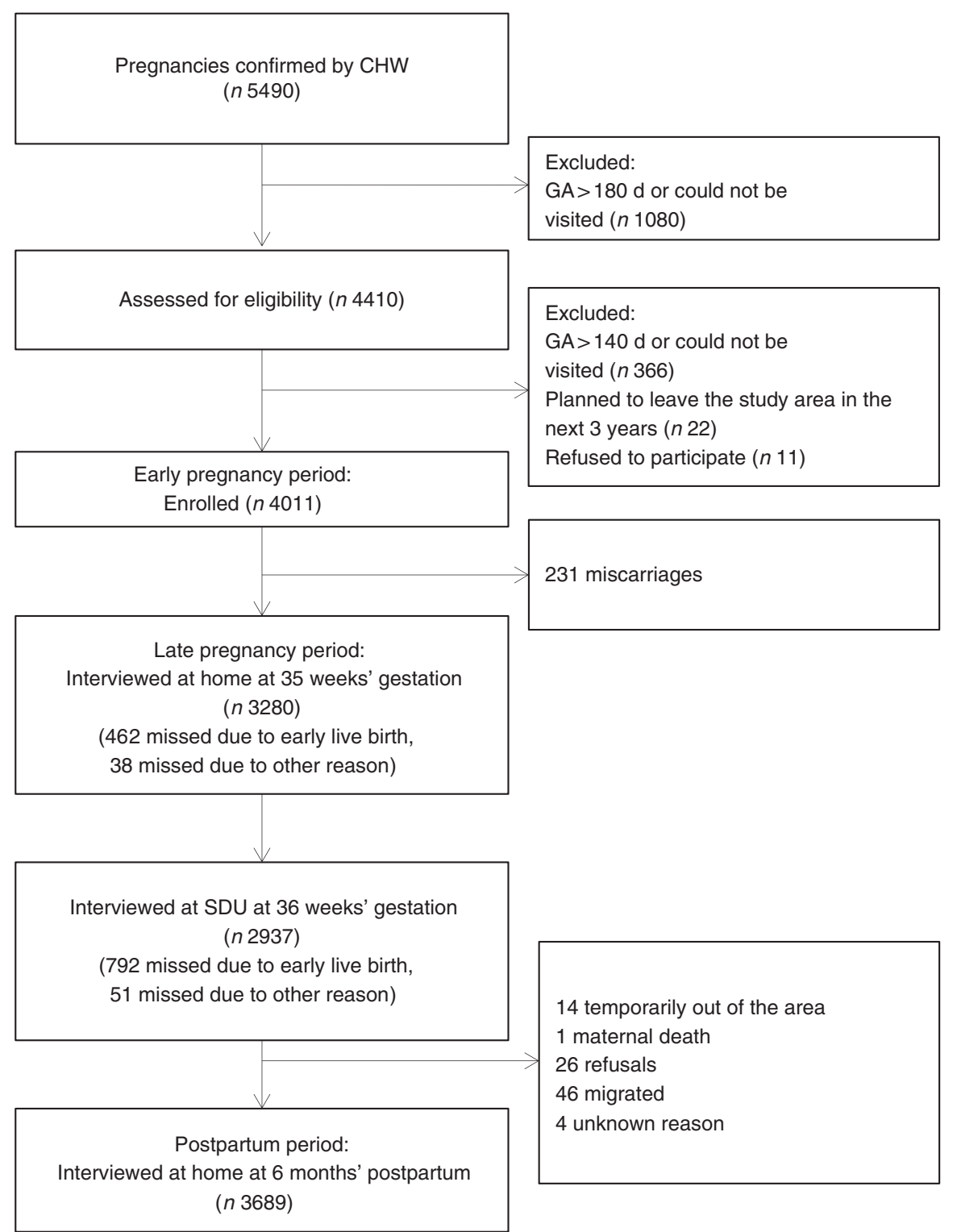

Fig. 1 Flowchart of participants (CHW, community health worker; GA, gestational age; SDU, safe delivery unit)

One loses willingness to take even a little more than the usual amount of rice and pulses. And if one takes, she cannot even move at all.'

\section{Implications of 'eating less' with regard to diet quality}

On average, all women consumed nutrient-dense foods such as ASF (mean (SD): $10 \cdot 8$ (7.8) times/week) and RGLV (5.0 (4.8) times/week; Table 5). The primary sources of ASF were fish, eggs and milk (see online supplementary material, Supplemental Table 2). Green leafy vegetables were more commonly consumed than red leafy vegetables. There was some degree of seasonal variation in the consumption of all the foods evaluated, which was most distinct for fruits (data not shown).

Women who reported eating less food overall in late pregnancy also reported eating less of most of the specific food items assessed (Table 6). In particular, women who reported eating less overall had greater odds of eating less meat $(\mathrm{OR}=2 \cdot 28 ; 95 \%$ CI $1.93,2 \cdot 68)$, fish $(\mathrm{OR}=2 \cdot 22 ; 95 \%$ CI $1 \cdot 88,2 \cdot 63)$ and poultry $(\mathrm{OR}=2 \cdot 00 ; 95 \% \mathrm{CI} 1 \cdot 70,2 \cdot 34)$ compared with women who did not report eating less.

The frequency of consumption of ASF, lentils and RGLV differed significantly between the three time periods $(P \leq 0.002$ for all). The frequency of consumption of each was highest in late pregnancy and lowest in the postpartum period. Maternal report of eating more overall was significantly associated with more frequent consumption of ASF and lentils across all time periods (Table 5). When stratified by time period, eating more was also significantly associated with more frequent RGLV consumption.

The most common foods that women reported avoiding across all time periods were duck and other 
meats and eggs (see online supplementary material, Supplemental Table 3). Among those who reported avoiding foods during early pregnancy, 32\% avoided fish and $12 \%$ avoided spinach (leafy vegetables). Pineapple was avoided by $35 \%$ and papaya by $19 \%$ of respondents who reported avoiding foods during late pregnancy.

Table 1 Baseline characteristics of the study population of rural Bangladeshi women ( $n$ 4011), Rang-Din Nutrition Study, September 2011-August 2012

\begin{tabular}{|c|c|c|}
\hline Characteristic & Mean or $\%$ & SD \\
\hline Gestational age at enrolment (weeks) & $13 \cdot 1$ & $3 \cdot 4$ \\
\hline \multicolumn{3}{|l|}{ Age group (\%) } \\
\hline $13-19$ years & 38.7 & - \\
\hline $20-24$ years & 33.7 & - \\
\hline$\geq 25$ years & $27 \cdot 6$ & - \\
\hline Nülliparous (\%) & $40 \cdot 9$ & - \\
\hline \multicolumn{3}{|l|}{ BMl category (\%) } \\
\hline$<18.5 \mathrm{~kg} / \mathrm{m}^{2}$ & 28.5 & - \\
\hline $18.5-24.9 \mathrm{~kg} / \mathrm{m}^{2}$ & $66 \cdot 0$ & - \\
\hline$\geq 25 \cdot 0 \mathrm{~kg} / \mathrm{m}^{2}$ & 5.5 & - \\
\hline Stature $<145 \mathrm{~cm}(\%)$ & $15 \cdot 5$ & - \\
\hline Mid-upper arm circumference $(\mathrm{cm})$ & 24.9 & $2 \cdot 6$ \\
\hline \multicolumn{3}{|l|}{ Education (\%) } \\
\hline No education & $9 \cdot 0$ & - \\
\hline Primary incomplete & 18.4 & - \\
\hline Primary complete & $14 \cdot 2$ & - \\
\hline Secondary incomplete & $45 \cdot 1$ & - \\
\hline Secondary complete or higher & $13 \cdot 4$ & - \\
\hline \multicolumn{3}{|l|}{ Religion (\%) } \\
\hline Muslim & $80 \cdot 5$ & - \\
\hline Hindu/Sonaton & $18 \cdot 7$ & - \\
\hline Christian & 0.8 & - \\
\hline Buddhist & $0 \cdot 1$ & - \\
\hline \multicolumn{3}{|l|}{ Season at enrolment (\%) } \\
\hline Summer (grisma) & $18 \cdot 1$ & - \\
\hline Rainy season (barsa) & $18 \cdot 6$ & - \\
\hline Autumn (sharat) & $10 \cdot 9$ & - \\
\hline Late autumn (hemanta) & $14 \cdot 6$ & - \\
\hline Winter (shit) & 19.5 & - \\
\hline Spring (basanta) & $18 \cdot 2$ & - \\
\hline
\end{tabular}

Implications of an 'eating less' diet pattern with regard to weight gain during pregnancy

Overall, women gained on average 6.37 (2.82) kg (mean (SD); median (interquartile range): $6.30(4.55-8.15) \mathrm{kg}$ ) from enrolment through the late pregnancy assessment visit at $\sim 36$ weeks, which translates into roughly $0.29 \mathrm{~kg} /$ week. Diet pattern in late pregnancy was significantly associated with weekly weight gain during pregnancy (Fig. 2). Women who reported eating less gained $0.06 \mathrm{~kg}$ less per week compared with women who reported eating more $(P<0.001)$. After adjusting for the woman's age, BMI and gestational age at enrolment, parity and season, the difference was attenuated to $0.05 \mathrm{~kg} /$ week $(P<0.001)$, which translates to $1.28(0.16) \mathrm{kg}$ (mean (SE)) throughout the observed period of pregnancy. Weekly weight gain among women who reported eating less was also lower compared with women who reported eating the same, and this difference also remained significant in the adjusted model (Fig. 2).

\section{Discussion}

The practice of eating less food during early and late pregnancy was highly prevalent in this population (76 and $39 \%$, respectively) and had negative implications with regard to diet quality as well as weight gain during pregnancy. In contrast, eating down during early and late pregnancy was not a common practice $(0.9$ and $3.7 \%$, respectively), and the prevalence was notably lower than what has been reported in other studies in similar contexts $^{(7,8,17)}$, which suggests that there may be some generational shift in this behaviour. Data from the in-depth interviews suggest that while eating down was not common, women may still be receiving advice regarding eating down, given some of the beliefs reported by family members.

Table 2 Reported diet patterns for eating less in early pregnancy, late pregnancy and postpartum* among rural Bangladeshi women (n 4011), Rang-Din Nutrition Study, September 2011-August 2012

\begin{tabular}{|c|c|c|c|c|c|c|c|c|c|}
\hline \multirow[b]{2}{*}{ Diet pattern } & \multirow{2}{*}{$\begin{array}{l}\text { Early } \\
\text { pregnancy } \\
(n \text { 4011) }\end{array}$} & \multirow{2}{*}{$\begin{array}{l}\text { Late } \\
\text { pregnancy } \\
\text { (n 3280) }\end{array}$} & \multirow{2}{*}{$\begin{array}{l}6 \text { months' } \\
\text { postpartum } \\
\text { (n } 3685)\end{array}$} & \multirow[b]{2}{*}{$P$} & \multicolumn{2}{|c|}{ Early pregnancy } & \multicolumn{2}{|c|}{ Late pregnancy } & \multirow{2}{*}{$\begin{array}{l}6 \text { months' } \\
\text { postpartum }\end{array}$} \\
\hline & & & & & OR & $95 \% \mathrm{Cl}$ & OR & $95 \% \mathrm{Cl}$ & \\
\hline \multicolumn{10}{|l|}{ Amount† (\%) } \\
\hline Less & $75 \cdot 9^{a}$ & $38 \cdot 8^{\mathrm{b}}$ & $7 \cdot 4^{\mathrm{c}}$ & $<0.001$ & 41.9 & $36 \cdot 2,48 \cdot 4$ & $8 \cdot 2$ & $7 \cdot 1,9 \cdot 4$ & Ref. \\
\hline Same & $16 \cdot 4$ & $25 \cdot 3$ & $40 \cdot 7$ & & & & & & \\
\hline More & $7 \cdot 8$ & 35.9 & 51.9 & & & & & & \\
\hline Eating down‡ (\%) & $0.9^{\mathrm{b}}$ & $3.7^{a}$ & $0.1^{\mathrm{c}}$ & $<0.001$ & & & & & \\
\hline \multicolumn{10}{|l|}{ Meals§ (\%) } \\
\hline Fewer & $34 \cdot 0^{\mathrm{a}}$ & $6 \cdot 1^{b}$ & $2 \cdot 7^{c}$ & $<0.001$ & $19 \cdot 2$ & $15 \cdot 4,23 \cdot 8$ & $2 \cdot 4$ & $1 \cdot 8,3 \cdot 0$ & Ref. \\
\hline Same & $46 \cdot 1$ & 41.0 & 67.4 & & & & & & \\
\hline More & 19.9 & 52.9 & $30 \cdot 0$ & & & & & & \\
\hline Avoiding specific foods (\%) & $24 \cdot 9^{b}$ & $21 \cdot 0^{C}$ & $42 \cdot 8^{a}$ & $<0.001$ & 0.4 & $0.4,0.5$ & 0.4 & $0.3,0.4$ & Ref. \\
\hline
\end{tabular}


Table 3 Reported reasons for eating less food ${ }^{\star}$ among the rural Bangladeshi women who reported the behaviour, Rang-Din Nutrition Study, September 2011-August 2012

\begin{tabular}{|c|c|c|c|c|}
\hline & $\begin{array}{c}\text { Early } \\
\text { pregnancy } \\
(n 3044) \dagger\end{array}$ & $\begin{array}{c}\text { Late } \\
\text { pregnancy } \\
(n \text { 1274) } \dagger\end{array}$ & $\begin{array}{l}6 \text { months' } \\
\text { postpartum } \\
(n 271) \dagger\end{array}$ & $\begin{array}{c}\text { Total } \\
(n \text { 4589) } \dagger\end{array}$ \\
\hline Reasons provided & $\%$ & $\%$ & $\%$ & $\%$ \\
\hline Food aversions/loss of appetite & $84 \cdot 0$ & $55 \cdot 0$ & 74.5 & $75 \cdot 4$ \\
\hline Illness & $53 \cdot 3$ & $42 \cdot 5$ & $35 \cdot 4$ & $49 \cdot 2$ \\
\hline Nausea and/or vomiting & $55 \cdot 3$ & 14.7 & 3.3 & 41.0 \\
\hline Less hungry & $9 \cdot 4$ & $13 \cdot 9$ & $10 \cdot 0$ & $10 \cdot 7$ \\
\hline Feels discomfort while eating & 1.4 & $8 \cdot 3$ & 0.4 & 3.3 \\
\hline Concerned about her own health & 1.0 & 8.6 & 0.4 & $3 \cdot 1$ \\
\hline $\begin{array}{l}\text { Feels full from less food/doesn't need as much } \\
\text { food }\end{array}$ & 0.1 & $5 \cdot 2$ & 0.7 & 1.6 \\
\hline Difficulty moving & $0 \cdot 1$ & $5 \cdot 3$ & 0.0 & 1.5 \\
\hline Poverty & 0.3 & 0.7 & 8.9 & 0.9 \\
\hline
\end{tabular}

${ }^{*}$ Reasons provided by women were included here if reported by $5 \%$ or more during any time period. The sum of the percentages is greater than the total in the group because women were allowed to provide multiple reasons.

†Percentage of those who reported eating less food during the time period.

Food aversions, loss of appetite, illness, and nausea and/ or vomiting were the most common reasons pregnant women gave for eating less, symptoms that are common among even otherwise healthy pregnant women. Given the high proportion of women who consumed less in this context, and the health implications for the woman and fetus, ways to address these barriers should be considered. We did not identify any studies that attempted to improve maternal dietary intake during pregnancy by addressing such barriers. Previous studies have evaluated the effect of ginger and vitamin $\mathrm{B}_{6}$ on reducing nausea and vomiting during pregnancy, and in a recent review ginger was effective at reducing pregnancy-induced nausea and vomiting ${ }^{(22,23)}$.

The prevalence of nausea and vomiting in the previous $14 \mathrm{~d}$ reported in late pregnancy (at 35 weeks' gestation) in this population was 29 and $18 \%$, respectively (data not shown) and $15 \%$ of women reported nausea and vomiting as the reason for decreased food consumption in our study. These data may suggest a higher prevalence of these symptoms than what has been previously reported in similar populations. In Nepal, nausea in the previous $7 \mathrm{~d}$ was reported among $6.2 \%$ of un-supplemented women in the third trimester and vomiting among $3.7 \%{ }^{(24)}$. The percentage of women in the current study who reported illness as a reason for decreasing intake in late pregnancy ( $42 \%$ of women eating less; $16 \%$ of all women) was notable. In a study conducted in Gaibandha, Bangladesh among women in their first trimester of pregnancy ( $n$ 42896), the most common symptoms reported in descending order were weakness that affected work, poor appetite, vaginal discharge, nausea, breathlessness, low-grade fever, lower abdominal pain and vomiting, and the most common illnesses reported in descending order were anaemia, morning sickness and excessive vomiting ${ }^{(25)}$. In a study from Sarlahi, Nepal, urinary or reproductive tract infection, lower abdominal pain, faintness and shortness of breath were common illnesses reported among women >28 weeks' gestation $(n \text { 7916) })^{(24)}$. These other studies provide ideas of what illnesses the current study population may have experienced, as we did not examine this. Further investigation is needed to understand how these conditions can be alleviated. The high reported prevalence of illness as a reason for eating less might be due to a loss of appetite, in which case addressing the causes of illness may be adequate to increase intake during pregnancy, although there may be cultural beliefs or norms that prevent increased intake that should not be discounted. The indepth interviews suggested a high awareness that eating more during pregnancy is beneficial, yet women felt that they were not able to consume more. This perception warrants further investigation.

Consumption of small, frequent meals is often recommended for pregnant women ${ }^{(26-28)}$, which we found to be widely known in this population. The weekly frequency of consumption of most food items was highest during late pregnancy, although the number of days per week that foods were consumed was fairly consistent over time, which may suggest that women were following the advice to increase the frequency of intake within a day during pregnancy. However, the portion sizes of micronutrientrich foods are typically small in this population ${ }^{(5)}$, so achieving micronutrient adequacy is unlikely even if the frequency of consumption has increased. Moreover, it is concerning that the frequency of ASF, lentil and RGLV intake was significantly lower among those who reported eating less food. While we did not ask women specifically about changing patterns of rice consumption, it is likely that women who reported eating less food overall were also consuming less rice. With rice being the major component of the diet and source of energy in this context, consuming less rice could have influenced achieving adequate energy intake during pregnancy, something we did not explore. 
Table 4 Prevalence of eating less in late pregnancy by baseline personal and family characteristics among rural Bangladeshi women (n 4011), Rang-Din Nutrition Study, September 2011-August 2012

\begin{tabular}{|c|c|c|c|c|c|c|}
\hline & \multirow[b]{2}{*}{ Total $(n)$} & \multicolumn{2}{|c|}{ Eating less* } & \multirow[b]{2}{*}{ OR† } & \multirow[b]{2}{*}{$95 \% \mathrm{Cl}$} & \multirow[b]{2}{*}{$P$} \\
\hline & & $n$ & $\%$ & & & \\
\hline \multicolumn{7}{|l|}{ Parity } \\
\hline Primigravid & 1276 & 404 & $31 \cdot 7$ & 0.59 & $0.51,0.69$ & $<0.001$ \\
\hline Multigravid & 1906 & 832 & 43.7 & 1.00 & Ref. & \\
\hline \multicolumn{7}{|l|}{ Age group } \\
\hline$<20$ years & 1287 & 440 & $34 \cdot 2$ & 0.71 & $0.61,0.82$ & $<0.001$ \\
\hline$\geq 20$ years & 1993 & 834 & $41 \cdot 8$ & 1.00 & Ref. & \\
\hline \multicolumn{7}{|l|}{ Previous stillbirth } \\
\hline Yes & 191 & 85 & 44.5 & 1.28 & $0.95,1.74$ & 0.11 \\
\hline No & 2986 & 1150 & 38.5 & 1.00 & Ref. & \\
\hline \multicolumn{7}{|l|}{ BMI category } \\
\hline$<18.5 \mathrm{~kg} / \mathrm{m}^{2}$ & 944 & 355 & $37 \cdot 6$ & 0.92 & $0.78,1.08$ & 0.31 \\
\hline$\geq 18.5 \mathrm{~kg} / \mathrm{m}^{2}$ & 2336 & 919 & 39.3 & 1.00 & Ref. & \\
\hline \multicolumn{7}{|l|}{ Stature } \\
\hline$<145 \mathrm{~cm}$ & 497 & 203 & $40 \cdot 8$ & 0.90 & $0.74,1.10$ & 0.29 \\
\hline$\geq 145 \mathrm{~cm}$ & 2783 & 1071 & $38 \cdot 5$ & 1.00 & Ref. & \\
\hline \multicolumn{7}{|l|}{ Mid-upper arm circumference } \\
\hline$<22 \mathrm{~cm}$ & 378 & 130 & 34.4 & 0.81 & $0.65,1.03$ & 0.08 \\
\hline$\geq 22 \mathrm{~cm}$ & 2807 & 1106 & 39.4 & 1.00 & Ref. & \\
\hline \multicolumn{7}{|l|}{ Education } \\
\hline At or below primary school & 1315 & 596 & $45 \cdot 3$ & 1.51 & $1 \cdot 30,1.75$ & $<0.001$ \\
\hline Beyond primary school & 1965 & 678 & 34.5 & 1.00 & Ref. & \\
\hline \multicolumn{7}{|l|}{ Religion } \\
\hline Other & 648 & 252 & 38.9 & 1.02 & $0.84,1.23$ & 0.87 \\
\hline Islam & 2632 & 1022 & 38.8 & 1.00 & Ref. & \\
\hline \multicolumn{7}{|l|}{ Family type } \\
\hline Joint & 860 & 291 & 33.8 & 0.71 & $0.60,0.83$ & $<0.001$ \\
\hline Single & 2420 & 983 & $40 \cdot 6$ & 1.00 & Ref. & \\
\hline Food security & & & & & & \\
\hline Severe food insecurity & 284 & 125 & $44 \cdot 0$ & 1.45 & $1.11,1.88$ & 0.006 \\
\hline Moderate food insecurity & 933 & 425 & $45 \cdot 6$ & 1.35 & $0.99,1.83$ & 0.057 \\
\hline Mild food insecurity & 486 & 180 & $37 \cdot 0$ & 0.98 & $0.75,1.29$ & 0.887 \\
\hline Food secure & 1577 & 544 & 34.5 & 1.00 & Ref. & \\
\hline Symptoms experienced at enrolment & & & & & & \\
\hline Vomiting & & & & & & \\
\hline Yes & 1468 & 588 & $40 \cdot 1$ & $1 \cdot 11$ & $0.96,1.29$ & 0.16 \\
\hline No & 1716 & 647 & $37 \cdot 7$ & 1.00 & Ref. & \\
\hline Vertigo & & & & & & \\
\hline Yes & 2148 & 849 & 39.5 & $1 \cdot 10$ & $0.94,1.28$ & 0.26 \\
\hline No & 1036 & 386 & $37 \cdot 3$ & 1.00 & Ref. & \\
\hline No appetite & & & & & & \\
\hline Yes & 2075 & 828 & 39.9 & $1 \cdot 15$ & $0.99,1.34$ & 0.076 \\
\hline No & 1108 & 407 & $36 \cdot 7$ & 1.00 & Ref. & \\
\hline Belief that women should eat less duri & & & & & & \\
\hline Yes & 14 & 11 & $78 \cdot 6$ & $6 \cdot 22$ & $1 \cdot 70,22 \cdot 79$ & 0.006 \\
\hline No & 3266 & 1263 & 38.7 & 1.00 & & \\
\hline Women makes decisions about food $p$ & & & & & & \\
\hline No & 3148 & 1215 & 38.6 & 0.76 & $0.53,1.10$ & 0.15 \\
\hline Yes & 131 & 58 & $44 \cdot 3$ & 1.00 & Ref. & \\
\hline Also reported eating less in early preg & & & & & & \\
\hline Yes & 2530 & 1040 & $41 \cdot 1$ & 1.45 & $1.22,1.74$ & $<0.001$ \\
\hline No & 750 & 234 & $31 \cdot 2$ & 1.00 & Ref. & \\
\hline Season & & & & & & \\
\hline Summer (grisma) & 570 & 255 & 44.7 & 1.34 & $1.01,1.78$ & $<0.001$ \\
\hline Rainy season (barsa) & 619 & 284 & $45 \cdot 9$ & 1.40 & $1.06,1.86$ & 0.043 \\
\hline Autumn (sharat) & 599 & 238 & 39.7 & 1.05 & $0.79,1.39$ & 0.018 \\
\hline Late autumn (hemanta) & 599 & 197 & $32 \cdot 9$ & 0.77 & $0.58,1.03$ & 0.76 \\
\hline Winter (shit) & 562 & 175 & $31 \cdot 1$ & 0.72 & $0.54,0.96$ & 0.075 \\
\hline Spring (basanta) & 331 & 125 & $37 \cdot 8$ & 1.00 & Ref. & 0.028 \\
\hline & & Mean & SD & & & \\
\hline Gestational age at enrolment (weeks) & & $13 \cdot 1$ & 3.5 & $1.00 \ddagger$ & $1.00,1.00$ & 0.90 \\
\hline Asset index (range: $-4.09,7.99$ ) & & $-0 \cdot 2$ & $2 \cdot 1$ & $0.91 \ddagger$ & $0.90,1.00$ & $<0.001$ \\
\hline
\end{tabular}

Ref., reference category.

*Women who reported eating less food in late pregnancy compared with the pre-pregnancy diet.

tOR represent bivariate associations between each risk factor and the odds of 'eating less' using mixed-model regression and accounting for the design effect. $\ddagger$ The OR per one unit increase in gestational age at enrolment or asset index. 
Table 5 Frequency of consumption (times/week) of nutrient-dense food groups in the past week, stratified by pregnancy stage and selfreported comparison of current diet to pre-pregnancy diet, among rural Bangladeshi women ( $n$ 4011), Rang-Din Nutrition Study, September 2011-August 2012

\begin{tabular}{|c|c|c|c|c|c|c|c|c|c|c|c|c|c|c|c|c|c|}
\hline \multirow[b]{3}{*}{ Food group } & & & & & \multicolumn{13}{|c|}{ Comparison of current diet to pre-pregnancy diet } \\
\hline & \multicolumn{4}{|c|}{ All women } & \multicolumn{4}{|c|}{ Less } & \multicolumn{4}{|c|}{ Same } & \multicolumn{4}{|c|}{ More } & \multirow[b]{2}{*}{$P \neq$} \\
\hline & $n^{\star}$ & Mean & SD & $P \dagger$ & $n^{*}$ & Mean & SD & & $n^{*}$ & Mean & SD & & $n^{*}$ & Mean & SD & & \\
\hline ASF & 10972 & $10 \cdot 8$ & $7 \cdot 8$ & $<0.001$ & 4589 & $10 \cdot 1$ & $7 \cdot 2$ & B & 2986 & $10 \cdot 7$ & $7 \cdot 6$ & B & 3401 & $12 \cdot 0$ & 8.7 & A & $<0.001$ \\
\hline Early pregnancy & 4010 & $10 \cdot 0$ & $7 \cdot 2$ & & 3044 & 9.5 & $7 \cdot 1$ & $\mathrm{c}$ & 656 & $10 \cdot 7$ & $7 \cdot 3$ & B & 311 & $12 \cdot 5$ & $8 \cdot 1$ & A & $<0.001$ \\
\hline Late pregnancy & 3277 & $13 \cdot 2$ & 8.4 & a & 1274 & 11.7 & $7 \cdot 4$ & c & 830 & $13 \cdot 1$ & 8.3 & B & 1176 & 14.8 & 9.2 & A & $<0.001$ \\
\hline 6 months' postpartum & 3685 & $9 \cdot 7$ & 7.5 & c & 271 & 8.5 & 6.5 & B & 1500 & 9.4 & $7 \cdot 0$ & B & 1914 & $10 \cdot 1$ & 7.9 & A & $<0.001$ \\
\hline Lentils & 10976 & $2 \cdot 7$ & 3.5 & $<0.001$ & 4589 & 2.5 & 3.3 & B & 2986 & 2.5 & 3.4 & B & 3401 & $3 \cdot 1$ & 3.8 & A & $<0.001$ \\
\hline Early pregnancy & 4011 & 2.6 & 3.3 & $b$ & 3044 & $2 \cdot 4$ & 3.2 & B & 656 & $2 \cdot 9$ & 3.6 & A & 311 & 3.1 & 4.0 & A & $<0.001$ \\
\hline Late pregnancy & 3280 & 3.2 & 3.7 & a & 1274 & $2 \cdot 8$ & 3.5 & B & 830 & 2.7 & 3.3 & B & 1176 & 4.0 & 4.0 & A & $<0.001$ \\
\hline 6 months' postpartum & 3685 & $2 \cdot 4$ & 3.4 & b & 271 & 1.9 & 3.0 & B & 1500 & $2 \cdot 2$ & 3.3 & B & 1914 & 2.6 & 3.6 & A & $<0.001$ \\
\hline RGLV & 10372 & 5.0 & 4.8 & 0.002 & 4589 & 4.9 & 4.7 & A & 2986 & 4.6 & 4.6 & A & 3401 & 5.5 & $5 \cdot 1$ & A & 0.30 \\
\hline Early pregnancy & 3410 & 4.9 & 4.7 & $a, b$ & 3044 & 4.8 & 4.6 & B & 656 & 5.0 & 4.6 & B & 311 & 5.9 & 5.0 & A & $<0.001$ \\
\hline Late pregnancy & 3277 & $6 \cdot 1$ & $5 \cdot 1$ & a & 1274 & 5.4 & 4.7 & B & 830 & 5.8 & $5 \cdot 1$ & B & 1176 & $7 \cdot 0$ & $5 \cdot 5$ & A & $<0.001$ \\
\hline 6 months' postpartum & 3685 & $4 \cdot 1$ & 4.4 & $\mathrm{~b}$ & 271 & 3.8 & $4 \cdot 0$ & B & 1500 & 3.7 & 4.0 & B & 1914 & 4.5 & 4.6 & A & $<0.001$ \\
\hline
\end{tabular}

ASF, animal-source foods; RGLV, red and green leafy vegetables.

*Number of observations.

†Tests the difference between the three time points, controlling for season, accounting for the design effect and adjusting for multiple comparisons using the Tukey-Kramer method. Significant between-group differences at $P<0.05$ within a column are indicated with different lower-case superscript letters.

$\ddagger$ Tests the difference between the three diet patterns, adjusted as described above. Significant between-group differences at $P<0.05$ within a row indicated with different upper-case superscript letters.

Interestingly, the two most common foods women reportedly ate less of during late pregnancy compared with pre-pregnancy were pineapple and nuts. Yet, these foods were consumed rarely among this population at any time point. Pineapple was also spontaneously reported as an avoided food item by $35 \%$ of women who reportedly avoided foods in the late postpartum period. Approximately $72 \%$ of women who reported eating less pineapple said that they did so because it was less available and $68 \%$ of women who reported eating less nuts cited the same reason (data not shown). Illness and food aversion were also common reasons for consuming less of both nuts and pineapple, and concerns about health, religious beliefs and being a food that should be avoided during pregnancy were reasons women gave for consuming less pineapple.

Avoidance of certain foods was reported during all three time periods and was most common in the postpartum period. Taboos that result in avoidance of certain foods during pregnancy and early postpartum have been documented previously in Bangladesh ${ }^{(8,29,30)}$ and we found that taboos surrounding nutrient-dense foods such as eggs, fish, leafy greens and meats exist in this population. However, our data are limited in that they do not differentiate between the types of eggs, fish, leafy greens and meat. For example, if a woman reported that she was avoiding duck eggs, her response was coded as 'eggs', although she may have continued to eat other, generally available eggs. Nevertheless, what is distinct about the findings from the current study is the high prevalence of avoiding certain foods at 6 months' postpartum. Previous studies suggest strong taboos regarding food and maternal care in the early $(0-40 \mathrm{~d})$ postpartum ${ }^{(29,30)}$, but have not explored these beliefs and practices in the later postpartum period.
Weekly weight gain was significantly lower among women who reported eating less in late pregnancy compared with women who reported eating more or the same amount as before pregnancy. The Institute of Medicine recommends that normal-weight women gain, on average, $0.42 \mathrm{~kg} /$ week in the second and third trimester, and that underweight women gain an average of $0.51 \mathrm{~kg} /$ week $^{(26)}$. In our study, where the prevalence of underweight was $28 \%$, the mean weight gain was $0 \cdot 29 \mathrm{~kg} /$ week. While the difference among women who reported eating less was statistically significant compared with those who reported eating the same or more, the adjusted difference of $0.05 \mathrm{~kg} /$ week is quite small.

We identified several personal and household characteristics that were associated with eating less in late pregnancy in this context. We found that younger age ( $<20$ years old) and being primigravid were associated with decreased odds of reporting eating less, which may represent a demographic shift in changed knowledge or perspectives about diet during pregnancy. Adolescent women typically gain more weight during pregnancy than older women in developed countries ${ }^{(31)}$, although this is not necessarily the case in developing countries. In a more comparable setting to ours, younger women ( $<16$ years) in rural Nepal had a greater likelihood of mid-upper arm circumference decreasing throughout their pregnancy compared with older women (20-25 years) ${ }^{(32)}$. Similarly, another study reported that mid-upper arm circumference of teenagers in Bangladesh decreased from early pregnancy to postpartum in comparison to similar nonpregnant teenagers ${ }^{(33)}$. Thus, our finding that younger women are less likely to report eating less during late pregnancy is encouraging. 
Table 6 Association between reported eating less overall ${ }^{*}$ and eating less of specific food items* in late pregnancy among rural Bangladeshi women ( $n$ 4011), Rang-Din Nutrition Study, September 2011-August 2012

\begin{tabular}{|c|c|c|c|c|c|c|}
\hline \multirow[b]{2}{*}{ Eating less of each food item† } & \multirow{2}{*}{$\begin{array}{c}\begin{array}{c}\text { Total overall } \\
(n 3280)\end{array} \\
\%\end{array}$} & \multirow{2}{*}{$\begin{array}{l}\text { Eating less overall } \\
\frac{(n 1274)}{\%}\end{array}$} & \multirow{2}{*}{$\begin{array}{c}\begin{array}{c}\text { Not eating less overall } \\
(n 2006)\end{array} \\
\%\end{array}$} & \multicolumn{3}{|c|}{$\begin{array}{l}\text { Risk of eating less of specific foods } \\
\text { if eating less overall }\end{array}$} \\
\hline & & & & OR $\ddagger$ & $95 \% \mathrm{Cl}$ & $P$ \\
\hline Pineapple & $74 \cdot 2$ & $79 \cdot 4$ & $70 \cdot 8$ & 1.70 & $1.43,2.02$ & $<0.001$ \\
\hline Nuts & $50 \cdot 2$ & $54 \cdot 1$ & $47 \cdot 8$ & 1.29 & $1.12,1.48$ & $<0.001$ \\
\hline Other dairy & $49 \cdot 7$ & $53 \cdot 1$ & 47.6 & 1.24 & $1.08,1.43$ & 0.002 \\
\hline Dried fish & $46 \cdot 6$ & 51 & $43 \cdot 8$ & 1.37 & $1.19,1.58$ & $<0.001$ \\
\hline Tomato & $40 \cdot 6$ & $40 \cdot 4$ & $40 \cdot 7$ & 0.97 & $0.83,1.13$ & 0.69 \\
\hline Mango & $39 \cdot 3$ & $42 \cdot 6$ & $37 \cdot 2$ & 1.26 & $1.09,1.47$ & 0.002 \\
\hline Indian jujubes & $36 \cdot 1$ & 34.9 & $36 \cdot 8$ & 0.92 & $0.79,1.08$ & 0.31 \\
\hline Cauliflower & $35 \cdot 3$ & $37 \cdot 7$ & 33.7 & $1 \cdot 19$ & $1.02,1.39$ & 0.027 \\
\hline Guava & $34 \cdot 3$ & $43 \cdot 3$ & 28.5 & 1.95 & $1 \cdot 67,2 \cdot 27$ & $<0.001$ \\
\hline Red leafy vegetables & 33.4 & $37 \cdot 3$ & 30.9 & 1.31 & $1.13,1.52$ & $<0.001$ \\
\hline Banana & $30 \cdot 4$ & $36 \cdot 3$ & $26 \cdot 7$ & 1.57 & $1.35,1.83$ & $<0.001$ \\
\hline Meat & 25.4 & 34.9 & $19 \cdot 3$ & $2 \cdot 28$ & $1.93,2.68$ & $<0.001$ \\
\hline Poultry & $25 \cdot 3$ & 33.4 & $20 \cdot 1$ & 2.00 & $1 \cdot 70,2 \cdot 34$ & $<0.001$ \\
\hline Eggs & $23 \cdot 8$ & 29.5 & $20 \cdot 1$ & 1.59 & $1 \cdot 35,1 \cdot 88$ & $<0.001$ \\
\hline Fish & 23.4 & $32 \cdot 1$ & $17 \cdot 8$ & $2 \cdot 22$ & $1.88,2.63$ & $<0.001$ \\
\hline Milk & $22 \cdot 9$ & $26 \cdot 1$ & 20.9 & 1.31 & $1 \cdot 10,1.55$ & 0.002 \\
\hline Lentils & $19 \cdot 2$ & $24 \cdot 1$ & $16 \cdot 2$ & 1.66 & $1.98,1.39$ & $<0.001$ \\
\hline Green leafy vegetables & $7 \cdot 2$ & $9 \cdot 2$ & $6 \cdot 0$ & 1.56 & $1.19,2.04$ & 0.001 \\
\hline
\end{tabular}

${ }^{*}$ Compared with the pre-pregnancy diet.

†Data were missing on eggs $(n 1)$, milk ( $n 1)$, nuts $(n 2)$, Indian jujubes $(n 1)$, guava $(n 4)$, pineapple $(n 2)$, cauliflower $(n 2)$, tomato $(n 2)$ and red leafy vegetables ( $n$ 2).

ҒOR represent the risk of eating less of each food item comparing those who ate less with those who did not eat less, calculated using mixed-model logistic regression, including the random effect of cluster. The models for eating less poultry, other dairy and nuts did not include the random effect of cluster due to a failure in the model to converge.

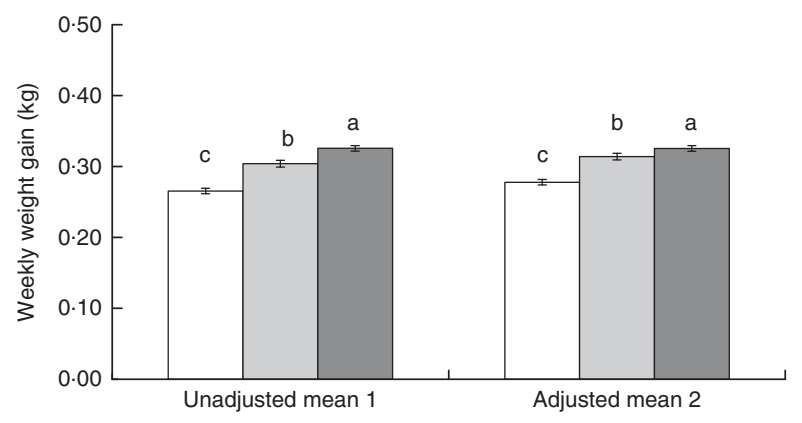

Fig. 2 Weekly weight gain during pregnancy (mean values with their standard errors represented by vertical bars) among rural Bangladeshi women ( $n$ 4011) who reported consuming less $(\square)$, the same $(\square)$ or more $(\square)$ food relative to their prepregnancy pattern, Rang-Din Nutrition Study, September 2011August 2012. Means in model 1 were calculated using mixedmodel ANOVA including the random effect of cluster and adjusted for multiple comparisons. Model 2 further adjusted for maternal age, BMl and gestational age at enrolment, parity, and season of interview at 36 weeks' gestation. ${ }^{\mathrm{a}, \mathrm{b}, \mathrm{c}}$ Mean values with unlike superscript letters were significantly different $(P<0.05)$

Karim et al. suggested in 2002 that improvements in knowledge regarding increased food intake during pregnancy are necessary in Bangladesh ${ }^{(7)}$. While our data suggest that changing awareness of diet recommendations during pregnancy should be considered, the in-depth interview data from our study suggest that most women, family members and $\mathrm{CHW}$ were aware of the increased dietary needs for pregnant women. Furthermore, the prevalence of women who reported that they believed women should eat less during pregnancy in our study was small. It is possible that in the 14 years since Karim et al.'s publication, awareness of dietary needs during pregnancy has increased among women and their families. LAMB has been operating in the north-west region of Bangladesh since the 1970s and the Community Health and Development Program provides a number of services including behaviour change communication related to nutrition within its health services. There are additional health programmes that operate in this region, including BRAC, which also provides health and nutrition services. Thus, improvements in knowledge alone may have limited impact on increasing food intake in this population. Levay et al. came to similar conclusions in a recent study conducted in Dhaka ${ }^{(34)}$. In that ethnographic study, women were found to be knowledgeable regarding healthy eating practices during pregnancy, yet high food prices and high food insecurity were barriers to eating well. We also found that lower socio-economic status, less education, food insecurity and season were all strong risk factors for maternal report of eating less. Poverty was a commonly reported reason for eating less, particularly in the postpartum period, suggesting economic barriers to adequate food intake. Being in a joint family, possibly an indicator of greater social support or higher socio-economic status, was associated with lower odds of eating less. These findings support the well-established relationship between food security, season and nutritional status in Bangladesh $^{(35)}$. Although gender inequality and differential food allocation within households have been 
recognized previously as barriers to adequate nutrition in some contexts in South Asia ${ }^{(8,36,37)}$, these themes did not emerge from the participants in our study.

The present study has a number of important strengths and limitations. A strong longitudinal design, large sample size and novel compilation of analyses were implemented. It may be the first study to evaluate eating less during pregnancy and postpartum longitudinally, and to evaluate the association between this behaviour and diet quality as well as pregnancy weight gain. The combination of quantitative and qualitative methods allowed us to triangulate the perceptions of women, family members and health workers to more comprehensively understand beliefs about avoiding foods during pregnancy and the amount of food pregnant women should consume. Nevertheless, the study is limited by the fact that diet patterns and FFQ were based on maternal self-report, which is susceptible to social desirability bias ${ }^{(38,39)}$, and may have resulted in under-reporting of eating less. Further, we did not use a quantitative diet assessment tool (e.g. $24 \mathrm{~h}$ recall or weighed food record) and therefore our measures of dietary intake lack information on portion size. Thus, we cannot quantify how macro- or micronutrient intake changed over the time periods. The lack of quantitative dietary data is especially challenging because of the difference in the frequency of intake recommendations between pregnancy and postpartum, as pregnant women were advised to consume small frequent meals. Finally, there is the potential for selection bias in the late pregnancy period due to the large number of early births and miscarriages in this population. However, among the women with missing data in the late pregnancy period, $70.3 \%$ reported eating less food in the early pregnancy period, compared with $75.9 \%$ among all women in the early pregnancy period, suggesting similar reporting patterns in early pregnancy.

\section{Conclusion}

In conclusion, eating less during pregnancy is of concern in this population. We did not find strong sociocultural factors that predicted this behaviour, but rather food aversions, illness, and nausea and vomiting were reasons women provided for eating less. Maternal report of eating less has implications with regard to diet quality and maternal weight gain. Weight gain during pregnancy was low in this population overall. While poor weight gain is of greater concern in the second and third trimesters, the implications of eating less for diet quality are cause for concern in both early and late pregnancy due to the increased micronutrient requirements for healthy fetal development. Interventions that address barriers to eating more during pregnancy, such as food aversions and illness, may be successful at improving maternal weight gain during pregnancy, and thus have beneficial effects on the health of the mother and fetus. Awareness of the key risk factors for eating less can help efforts to target high-risk groups early in pregnancy or even prior to conception. In some contexts, nutrition and health education programmes are adequate to address dietary behaviour in pregnancy and postpartum. However, in this context our results suggest that eating less is not the result of a knowledge gap, but due to other barriers including socio-economic factors and access to foods. The strong seasonal component of food availability, dietary intake, maternal weight gain and prevalence of eating less in this context is noteworthy. Investigators and programme planners must focus on interventions designed to improve maternal health in ways that are affordable, available yearround, culturally and socially acceptable, and feasible. In addition, the underlying perceptions and barriers that drive behaviours such as eating less during pregnancy must be addressed.

\section{Acknowledgements}

Acknowledgements: The authors acknowledge Janet Peerson from UC Davis for her statistical advice; Lia Fernald from UC Berkeley, Joseph Cummins from UC Riverside, Louise Day from LAMB and Zeina MaaloufManasseh from FANTA for their technical inputs and feedback on the manuscript; the Rang-Din Nutrition Study Home Visit and SDU Visit Teams and LAMB for their dedication to implement the study; and the participants for their support and participation. Financial support: This study was carried out with funding from the Office of Health, Infectious Diseases, and Nutrition, Bureau for Global Health, US Agency for International Development (USAID) under terms of Cooperative Agreement No. AIDOAA-A-12-00005, through the Food and Nutrition Technical Assistance III Project (FANTA), managed by FHI 360, and from the National Institutes of Health (NIH) Research Training Grant \# R25 TW009343 funded by the Fogarty International Center, Office of Behavioral and Social Sciences Research, Office of Research on Women's Health, Office of AIDS Research, National Institute of Mental Health, and National Institute on Drug Abuse, as well as the University of California Global Health Institute. The contents of this article are the responsibility of the authors and do not necessarily reflect the views of USAID, NIH or the US Government. Conflict of interest: None declared. Authorship: All authors were involved in the design or implementation of the study and reviewed and approved the final manuscript. K.L.H. and C.P.S. led the analysis and interpretation with substantive inputs from K.G.D. and S.L.M. M.K.M. and S.A.V. provided contributions to the study design and interpretation. K.L.H., S.H. and M.K.M. were involved in the data collection. K.L.H. wrote the first draft of the manuscript with substantive inputs from C.P.S. and K.G.D. Ethics of buman subject participation: This study was approved by the UC Davis Institutional Review 
Board, the Ethical Review Committee of the International Center for Diarrhoeal Disease Research, Bangladesh and the LAMB Research Ethics Committee. Women indicated their written consent to participate in the study after a consent form was read to them. If a participant was less than 18 years old, her guardian signed the consent form on her behalf and participants who could not write provided consent with a thumbprint.

\section{Supplementary material}

To view supplementary material for this article, please visit https://doi.org/10.1017/S1368980017000672

\section{References}

1. Ramakrishnan U (2004) Nutrition and low birth weight: from research to practice. Am J Clin Nutr 79, 17-21.

2. Black RE, Allen LH, Bhutta ZA et al. (2008) Maternal and child undernutrition: global and regional exposures and health consequences. Lancet 371, 243-260.

3. Black RE, Victora CG, Walker SP et al. (2013) Maternal and child undernutrition and overweight in low-income and middle-income countries. Lancet 382, 427-451.

4. National Institute of Population Research and Training, Mitra and Associates, \& ICF International (2013) Bangladesh Demographic and Health Survey 2011. Dhaka and Calverton, MD: NIPORT, Mitra and Associates, and ICF International.

5. Arsenault JE, Yakes EA, Islam MM et al. (2013) Very low adequacy of micronutrient intakes by young children and women in rural Bangladesh is primarily explained by low food intake and limited diversity. J Nutr 143, 197-203.

6. Arsenault JE, Yakes EA, Hossain MB et al. (2010) The current high prevalence of dietary zinc inadequacy among children and women in rural Bangladesh could be substantially ameliorated by zinc biofortification of rice. J Nutr 140, 1683-1690

7. Karim R, Bhat D, Troy L et al. (2003) Determinants of Food Consumption During Pregnancy in Rural Bangladesh: Examination of Evaluative Data from the Bangladesh Integrated Nutrition Project. Discussion Paper no. 11. Boston, MA: Tufts University Friedman School of Nutrition Science and Policy; available at http://nutrition.tufts.edu/ pdf/publications/fpan/wp11-food_consumption.pdf

8. Shannon K, Mahmud Z, Asfia A et al. (2008) The social and environmental factors underlying maternal malnutrition in rural Bangladesh: implications for reproductive health and nutrition programs. Health Care Women Int 29, 826-840.

9. Hutter I (1996) Reduction of food intake during pregnancy in rural south India. Trop Med Int Health 1, 399-405.

10. Nichter M \& Nichter M (1983) The ethnophysiology and folk dietetics of pregnancy: a case study from South India. Hum Organ 42, 235-246.

11. Pool R (1987) Hot and cold as an explanatory model: the example of Bharuch district in Gujarat, India. Soc Sci Med 25, 389-399.

12. Rao M (1985) Food beliefs of rural women during the reproductive years in Dharwad, India. Ecol Food Nutr 16 , 93-103.

13. Mukhopadhyay S \& Sarkar A (2009) Pregnancy-related food habits among women of rural Sikkim, India. Public Health Nutr 12, 2317-2322.

14. Ali NS, Azam SI \& Noor R (2004) Women's beliefs and practices regarding food restrictions during pregnancy and lactation: a hospital based study. I Ayub Med Coll Abbottabad 16, 29-31.

15. Mahmood S, Atif MF, Mujeeb SS et al. (1997) Assessment of nutritional beliefs and practices in pregnant and lactating mothers in an urban and rural area of Pakistan. J Pak Med Assoc 47, 60-62.

16. Kusin JA, Kardjati S \& Renqvist UH (1994) Maternal body mass index: the functional significance during reproduction. Eur J Clin Nutr 48, Suppl. 3, S56-S67.

17. Christian P, Srihari SB, Thorne-Lyman A et al. (2006) Eating down in pregnancy: exploring food-related beliefs and practices of pregnancy in rural Nepal. Ecol Food Nutr $\mathbf{4 5}$, 253-278.

18. Mridha M, Matias S, Chaparro C et al. (2016) Lipid-based nutrient supplements for pregnant women reduce newborn stunting in a cluster-randomized controlled effectiveness trial in Bangladesh. Am J Clin Nutr 103, 236-249.

19. Coates J, Swindale A \& Bilinsky P (2007) Household Food Insecurity Access Scale (HFIAS) for Measurement of Food Access: Indicator Guide V.3. Washington, DC: Food and Nutrition Technical Assistance Project, Academy for Educational Development.

20. Harding KL, Matias SL, Mridha MK et al. (2017) Adherence to recommendations on lipid-based nutrient supplement and iron and folic acid tablet consumption among pregnant and lactating women participating in a community health programme in northwest Bangladesh. Matern Child Nutr 13, issue $1, \mathrm{e} 12252$.

21. Glaser BG \& Strauss AL (1967) The Discovery of Grounded Theory: Strategies for Qualitative Research. Chicago, IL: Aldine.

22. Ding M, Leach M \& Bradley H (2013) The effectiveness and safety of ginger for pregnancy-induced nausea and vomiting: a systematic review. Women Birth 26, e26-e30.

23. Sripramote M \& Lekhyananda N (2003) A randomized comparison of ginger and vitamin B6 in the treatment of nausea and vomiting of pregnancy. J Med Assoc Thai 86, 846-853.

24. Christian P, West KP Jr, Khatry SK et al. (2000) Vitamin A or $\beta$-carotene supplementation reduces symptoms of illness in pregnant and lactating Nepali women. J Nutr 130, $2675-2682$.

25. Kim JM, Labrique A, West KP et al. (2012) Maternal morbidity in early pregnancy in rural northern Bangladesh. Int J Gynaecol Obstet 119, 227-233.

26. Institute of Medicine, National Research Council (2009) Weight Gain During Pregnancy: Reexamining the Guidelines. Washington, DC: The National Academies Press.

27. Davis DC (1996) The discomforts of pregnancy. J Obstet Gynecol Neonatal Nurs 25, 73-81.

28. Power ML, Milligan LA \& Schulkin J (2007) Managing nausea and vomiting of pregnancy: a survey of obstetriciangynecologists. J Reprod Med 52, 922-928.

29. Choudhury N \& Ahmed SM (2011) Maternal care practices among the ultra poor households in rural Bangladesh: a qualitative exploratory study. BMC Pregnancy Childbirth 11, 15.

30. Goodburn EA, Gazi R \& Chowdhury M (1995) Beliefs and practices regarding delivery and postpartum maternal morbidity in rural Bangladesh. Stud Fam Plann 26, 22-32.

31. Hediger ML, Scholl TO \& Schall JI (1997) Implications of the Camden Study of adolescent pregnancy: interactions among maternal growth, nutritional status, and body composition. Ann N Y Acad Sci 817, 281-291.

32. Katz J, Khatry SK, LeClerq SC et al. (2010) The post-partum mid-upper arm circumference of adolescents is reduced by pregnancy in rural Nepal. Matern Child Nutr 6, 287-295.

33. Rah JH, Christian P, Shamim AA et al. (2008) Pregnancy and lactation hinder growth and nutritional status of adolescent girls in rural Bangladesh. $J$ Nutr 138, 1505-1511. 
34. Levay AV, Mumtaz Z, Faiz Rashid S et al. (2013) Influence of gender roles and rising food prices on poor, pregnant women's eating and food provisioning practices in Dhaka, Bangladesh. Reprod Health 10, 53.

35. Hillbruner C \& Egan R (2008) Seasonality, household food security, and nutritional status in Dinajpur, Bangladesh. Food Nutr Bull 29, 221-231.

36. Gittelsohn J \& Vastine AE (2003) Sociocultural and household factors impacting on the selection, allocation and consumption of animal source foods: current knowledge and application. J Nutr 133, 11 Suppl. 2, 4036S-4041S.
37. Miller BD (1997) Social class, gender and intrahousehold food allocations to children in South Asia. Soc Sci Med $\mathbf{4 4}$, $1685-1695$.

38. Stone AA, Bachrach CA, Jobe JB et al. (2009) The Science of Self-report: Implications for Research and Practice. Mahwah, NJ: Lawrence Erlbaum Associates, Inc.

39. Hebert JR, Clemow L, Pbert L et al. (1995) Social desirability bias in dietary self-report may compromise the validity of dietary intake measures. Int $J$ Epidemiol 24, 389-398. 